\title{
Genetic potential and variability for phenological and yield attributes in facultative winter wheat
}

\author{
Muhammad Ishaq ${ }^{1}$, Gulzar Ahmad ${ }^{1}$, Khilwat Afridi ${ }^{1}$, Murad Ali ${ }^{*}$, \\ Saeed Ullah' ${ }^{2}$, Hamid-ur-Rahman ${ }^{1}$, Tanzim Ullah Khan ${ }^{1}$, Muhammad \\ Adeel Qureshi ${ }^{1}$, Irfan Ahmad Shah ${ }^{1}$, Amir Saleem ${ }^{1}$ and Muhammad \\ Saeed $^{1}$ \\ 1. Cereal Crops Research Institute (CCRI), Pirsabak Nowshera KPK-Pakistan \\ 2. Departments of Agronomy, the University of Agriculture, Peshawar-Pakistan \\ *Corresponding author's email: muradses@gmail.com
}

Citation

Muhammad Ishaq, Gulzar Ahmad, Khilwat Afridi, Murad Ali, Saeed Ullah, Hamid-ur-Rahman, Tanzim Ullah Khan, Muhammad Adeel Qureshi, Irfan Ahmad Shah, Amir Saleem and Muhammad Saeed. Genetic potential and variability for phenological and yield attributes in facultative winter wheat. Pure and Applied Biology. Vol. 6, Issue 2, pp619-626. http://dx.doi.org/10.19045/bspab.2017.60064

\begin{tabular}{llll}
\hline \hline Received: 05/02/2017 & Revised: 14/04/2017 & Accepted: 25/04/2017 & Online First: 02/05/2017 \\
\hline
\end{tabular}

\section{Abstract}

To feed ever growing world population, development of high yielding and disease resistant wheat varieties are of utmost importance. A set of 20 genotypes including 18 facultative winter wheat lines and two checks (Pirsabak-2005 \& Pirsabak-2013) cultivar were evaluated at Cereal Crops Research Institute (CCRI), Pirsabak Nowshera Khyber Pakhtunkhwa-Pakistan during 2014-15 cropping season. Highly significant differences $(\mathrm{P} \leq 0.01)$ were found among the facultative lines for all traits except biological yield. Days to heading, maturity, plant height, biological yield, grain yield and harvest index varied from 116 to 133 days, 152 to 168 days and 87 to $128 \mathrm{~cm}, 11805.56$ to $16666.67 \mathrm{~kg} \mathrm{ha}^{-1}, 1627.78$ to $4713.89 \mathrm{~kg} \mathrm{ha}^{-1}$ and 15.11 to $36.00 \%$ respectively. Based on mean performance, FWWL-6 was found best for days to heading and maturity as it headed and matured earlier than other lines. For reduced height, FWWL-7 was found best. Comparison of mean for grain yield showed that FWWL-14 produced the highest grain yield (4713.89 $\mathrm{kg} \mathrm{ha}^{-1}$ ) as compared to other genotypes. Heritability estimates in broad sense for days to heading, maturity, plant height, grain yield, biological yield and harvest index was $0.81,0.59,0.86,0.26,0.70$ and 0.83 respectively. Genetic advance (\%) for days to heading, days to maturity, plant height, biological yield, grain yield and harvest index was 3.69, 2.61, $10.98,4.83,19.67$ and 22.93 respectively. High heritability estimates for all the traits except biological yield, suggested that selection would be more effective to develop superior lines that could be used in future wheat improvement programs.

Keywords: Correlation; Heritability (Broad sense); Wheat Potential; Winter wheat

Introduction

Wheat (Triticum aestivium L.) is one of the most important cereal crops because of its high nutritive value, unique characteristics and its uses in a variety of products. Worldwide wheat is grown in many 
ecological zones. In Pakistan wheat was grown over an area of 8.69 million hectares which produced 24.2 million tons with an average yield of $2787 \mathrm{~kg} \mathrm{ha}^{-1}$ while total area under wheat in Khyber Pakhtunkhwa was 0.72 million hectares [1]. The average yield of Khyber Pakhtunkhwa province (1807 kg ha-1) is much lower than the national average yield (2787 $\left.\mathrm{kg} \mathrm{ha} \mathrm{ha}^{-1}\right)$. Among other factors, one of the major issues for low wheat productivity in the province are unavailability of high yielding, disease resistant cultivars suited best to semiarid and arid environment.

Due to increase in population and current scenario of climatic change, demands of wheat are increasing consistently worldwide and in Pakistan. Therefore introducing new cultivars/ advanced lines with superior features like high yield, disease resistance and adaptation to arid and semiarid climates are the prerequisites (Brant., 2009) [2]. Development of new high yielding cultivars requires a thorough knowledge of the existing genetic variation for economically important traits, features of genotypes $(\mathrm{G})$, environment $(\mathrm{E})$ and $\mathrm{G} \times \mathrm{E}$ interaction. Ideal genotype having high grain yield or component traits needs to express genetic potential revealing the lowest value of variance $\left(\sigma^{2}\right)$ in diverse environmental growing factors. Yield is indeed a complex quantitative trait and selection on the basis of grain yield alone is in-effective as other component traits are not properly considered [3]. Therefore, identification of those characters which reveals significant contribution to final grain yield is indispensable for efficient wheat breeding. Likewise, characters which are easily measurable and showing healthy heritability values \& reflecting positive relationship with final yield have supreme importance to exercise indirect selection method for better yield [4]. If the heritability for a character is higher than the selection will become much easier and thus response to selection will be greater [5].

Wheat production must be increased by $40 \%$ till 2020 to meet the worldwide wheat demand. "Increasing the intensity of production in those ecosystems that lend themselves to sustainable intensification, while decreasing intensity of production in the more fragile ecosystems" could be the possible solution for agriculture to be maintained with growing population [6]. In addition, crop production enhancement really emphasized on grain yield potential (GYP), user preferences and stability of yield on a wide range of environments.

In the current study 18 wheat lines which were selected from 21- Facultative winter wheat observation nursery for semi-arid (FAWWON-SA) nursery along with two checks were grown at CCRI, Pirsabak with the key objectives to determine potential of promising selected Facultative winter wheat lines for phonological and yield attributes. Estimate the genotypic variation and heritability for the studied traits. Testing of promising selected lines in advanced trials and its utilization in future wheat breeding.

\section{Material and methods \\ Experimental material}

Facultative CIMMYT nursery (21FAWWONSA) was grown at CCRI, Pirsabak, during Rabi season 2013-14. Each line/ entry was composed of 2 rows having row length of 2 meter, with R-R spacing 30 $\mathrm{cm}$. Among the 108 lines only 18 promising lines were chosen on the basis of better performance for final grain yield and physiological maturity and were promoted for further testing to advanced yield trial.

\section{Experimental site}

The present research was carried out at experimental field of Wheat Breeding Section at CCRI, Pirsabak, Nowshera, with coordinates of $34^{0} \mathrm{~N}$ latitude, $72^{\circ} \mathrm{E}$ longitude and $288 \mathrm{~m}$ height of sea level Khyber Pakhtunkhwa-Pakistan during Rabi season 
of 2014-15. The physico-chemical properties of experimental site was $0.82 \%$ organic matter, $4.2 \mathrm{ppm}$ available phosphorous, $70 \mathrm{ppm}$ available potassium with $0.13 \mathrm{dSm}^{-1} \mathrm{EC}$ and $8.1 \mathrm{pH}$. Selected 18 facultative winter wheat lines (FWWL) along with the two check cultivars i.e. Pirsabak-2013 and Pirsabak-2005 were evaluated in randomized complete block design with two replications. The detail of the lines used the study is presented in Table 1. Each line was properly sown in six rows with 5 meter length; row space was kept as $30 \mathrm{~cm}$ while plot size was $9 \mathrm{~m}^{2}$. Standard agronomic practices were followed throughout the cropping season. Data were recorded on days to heading, physiological maturity, plant height, biological yield, grain yield and harvest index.

Table 1. Detail of the Facultative winter wheat lines (FWWL) used in the study

\begin{tabular}{|c|c|c|}
\hline $\begin{array}{l}\text { Genotype } \\
\text { Name }\end{array}$ & $\begin{array}{l}\text { Origin } \\
\text { 21-FWWON-SA } \\
(2013-14)\end{array}$ & Parentage \\
\hline FWWL-1 & FAWWON-V-3 & SONMEZ \\
\hline FWWL-2 & FAWWON-V-20 & WEEBILL1/NALIM-3//GALLYA-ARAL1 \\
\hline FWWL-3 & FAWWON-V-57 & GRK 79//SEAFALLH... \\
\hline FWWL-4 & FAWWON-V-60 & BEZOSTAYA \\
\hline FWWL-5 & FAWWON-V-61 & "KRASNOVODOPADSKAYA25/GRU-47" \\
\hline FWWL-6 & FAWWON-V-62 & "ZANDER-17/3/KAUZ*2/YACO//KAUZ" \\
\hline FWWL-7 & FAWWON-V-66 & $\begin{array}{l}\text { "TX71A983.4/TX69D4812//PYN/3/VPM/MOS83.11.4.8//PEW/ } \\
\text { 4/GRU-54" }\end{array}$ \\
\hline FWWL-8 & FAWWON-V-68 & "91-142 a 139" \\
\hline FWWL-9 & FAWWON-V-70 & $\begin{array}{l}\text { "CAR422/ANA//YACO/3/KAUZ*2/TRAP//KAUZ/4/BUCUR/ } \\
\text { 5/BUCUR" }\end{array}$ \\
\hline FWWL-10 & FAWWON-V-74 & $\begin{array}{l}\text { "NGDA146/4/YMH/TOB//MCD/3/LIRA/5/F130L1.12/6/Nalim } \\
\text {-3=BEZ//BEZ/TVR/3/KREMENA/ LOV29/4/KATYA1" }\end{array}$ \\
\hline FWWL-11 & FAWWON-V-76 & $\begin{array}{l}\text { "1-68-188//1-60-3/Tonichi } \\
\text { 81/4/885K4.1//MNG/SDV1/3/1D13.1/MLT" }\end{array}$ \\
\hline FWWL-12 & FAWWON-V-77 & $\begin{array}{l}\text { TX71A983.4/TX69D4812//PYN/3/VPM/MOS83.11.4.8//PEW/ } \\
\text { 4/MUSTANG }\end{array}$ \\
\hline FWWL-13 & FAWWON-V-78 & $\begin{array}{l}\text { TX71A983.4/TX69D4812//PYN/3/VPM/MOS83.11.4.8//PEW/ } \\
\text { 4/MUSTANG }\end{array}$ \\
\hline FWWL-14 & FAWWON-V-79 & $\begin{array}{l}\text { NOVOSADSKA/6/TX81V6614/5/RRV/WW15/3/BJ/2*ON//B } \\
\text { ON/4/NAC }\end{array}$ \\
\hline FWWL-15 & FAWWON-V-86 & KARL/OR8300764//RINA-6 \\
\hline FWWL-16 & FAWWON-V-92 & $\begin{array}{l}\text { TRAP\#1/YACO/3/KAUZ*2/TRAP//KAUZ/6/SN64//SKE/2*A } \\
\text { NE/3/SX/4/BEZ/5/JUN/7/SHARK-1 }\end{array}$ \\
\hline FWWL-17 & FAWWON-V-94 & POLOVCHANKA/PEHLIVAN \\
\hline FWWL-18 & FAWWON-V-102 & OK05204 \\
\hline Check-I & Pirsabak-2013 & CS/TH.SC//3*PVN/3/ MIRLO/BUC/4/MILAN /5/TILHI \\
\hline Check-II & Pirsabak-2005 & MUNIA/ SHTO//AMSEL \\
\hline
\end{tabular}

\section{Statistical analysis}

The recorded data was statistically analyzed using analysis of variance technique by using statistix 8.1 software. Differences among wheat genotypes for different traits were examined by using least significant differences (LSD) with $\mathrm{P}$ at 0.05 and 0.01 probability levels. 


\section{Heritability}

Broad sense heritability was calculated using the following formula.

$\mathrm{h}^{2}=\frac{V g}{V p}$

Where,

$\mathrm{h}^{2}=$ heritability broad based,

$\mathrm{Vg}=$ Genetic variance $=\frac{\text { MSG }- \text { MS }}{\mathrm{r}}$

$\mathrm{Vp}=$ Phenotypic variance $=\mathrm{Vg}+\mathrm{Ve}$

Where,

MSG= Mean squares due to genotypes

$\mathrm{MSE}=$ Mean squares due to error

$\mathrm{Ve}=$ Error variance

$\mathrm{r}=$ replication

\section{Genetic advance (GA)}

Genetic advance (GA) was calculated by mentioned formula described by [7].

Genetic Advance $=\mathrm{i} 6 \mathrm{ph}^{2}$

Similarly,

I is the selection intensity and its value is

1.75 at 10

$6 \mathrm{p}$ is the phenotypic std. deviation

$\mathrm{h}^{2}{ }_{(\mathrm{B} . S)}=$ heritability Broad based.

\section{Results and discussion}

\section{Days to heading}

In wheat earlier spike initiation is desired and wheat scientists are more concerned to develop new highly adapted wheat genotypes with earlier heading. Analysis of the data revealed significant differences $(\mathrm{P} \leq$ 0.01 ) among the wheat genotypes for heading (Table 2). Highly significant genetic differences have also been reported by Abinasa et al. [8] in evaluating 24 sets of wheat genotypes for morphological traits including heading, maturity and grain yield. Similarly, Tesfaye et al. [9] also reported highly significant genetic differences in advanced bread-wheat lines for days to heading and harvest plus under well water conditions. Days to heading was ranging from 116 to 133 days, having average value (122 days). Wheat genotype FWW-6 was desired with its least days of 116 to heading (Table 3). Genotypic, phenotypic as well as error variance were $12.73,15.72$ and 2.99 respectively. Broad sense heritability for days to heading was high (0.81). High value for days to heading trait was also previously reported by Tazeen et al. [10]. Hence higher values of heritability reflect the reliability and availing the supreme chance of the genotypes to be identified by its physical appearances [11]. Genetic advance was low (3.69\%) for heading (Table 4). Low genetic advance was also reported by [8] in spring wheat experiment evaluated for augmenting the agronomic traits including heading. In addition, medium to low heritability for important traits including heading was observed by Gupta and Verma [12] and suggested that selection should be effective either with high heritability in wheat.

Table 2. ANOVA for phenological as well as yield traits in selected facultative winter wheat lines (FWWL)

\begin{tabular}{|l|l|l|l|l|}
\hline & & Mean squares & & \\
\hline Traits & Genotypes & Replications & Error & CV (\%) \\
\hline Days to heading & $50.28^{* *}$ & 2.99 & 12.10 & 1.42 \\
\hline Days to maturity & $46.56^{* *}$ & 0.90 & 10.64 & 2.03 \\
\hline Plant height & $264.26^{* *}$ & 15.63 & 13.15 & 3.36 \\
\hline Biological yield & $3449480.18 \mathrm{NS}$ & 625000.00 & 2667722.55 & 11.37 \\
\hline Grain yield & $1189168.08^{* *}$ & 918.40 & 173683.19 & 11.16 \\
\hline Harevst index & $67.38^{* *}$ & 0.21 & 4.73 & 8.29 \\
\hline
\end{tabular}

NS =Non- Significant $\quad * *$ highly significant at $1 \%$ level of probability 
Table 3. Mean performance for phenological and yield traits of twenty facultative winter wheat genotypes

\begin{tabular}{|c|c|c|c|c|c|c|}
\hline Genotypes & $\begin{array}{l}\text { Days to } \\
\text { heading }\end{array}$ & $\begin{array}{l}\text { Days to } \\
\text { maturity }\end{array}$ & $\begin{array}{l}\text { Plant } \\
\text { height }(\mathrm{cm})\end{array}$ & $\begin{array}{l}\text { Biological yield } \\
\left(\mathrm{kg} \mathrm{ha}^{-1}\right)\end{array}$ & $\begin{array}{l}\text { Grain yield } \\
\left(\mathrm{kg} \mathrm{ha}^{-1}\right)\end{array}$ & $\begin{array}{l}\text { Harvest } \\
\text { index }(\%)\end{array}$ \\
\hline FWWL-1 & 121 & 161 & 126.5 & 16666.67 & 3705.56 & 22.15 \\
\hline FWWL-2 & 125 & 163 & 125.5 & 15277.78 & 3908.33 & 25.44 \\
\hline FWWL-3 & 133 & 168 & 123.5 & 14583.33 & 1627.78 & 11.17 \\
\hline FWWL-4 & 129 & 165 & 103.0 & 15277.78 & 3600.00 & 23.54 \\
\hline FWWL-5 & 131 & 166 & 105.5 & 14583.33 & 3808.33 & 26.52 \\
\hline FWWL-6 & 116 & 152 & 102.5 & 13888.89 & 4588.89 & 33.04 \\
\hline FWWL-7 & 119 & 155 & 87.0 & 11805.56 & 3556.94 & 30.09 \\
\hline FWWL-8 & 120 & 160 & 97.0 & 15277.78 & 3950.00 & 25.85 \\
\hline FWWL-9 & 120 & 156 & 102.5 & 13194.44 & 4033.33 & 30.58 \\
\hline FWWL-10 & 119 & 155 & 96.5 & 11805.56 & 3388.89 & 28.74 \\
\hline FWWL-11 & 117 & 158 & 102.5 & 13888.89 & 3744.44 & 26.96 \\
\hline FWWL-12 & 122 & 162 & 110.0 & 16666.67 & 3944.44 & 23.88 \\
\hline FWWL-13 & 122 & 165 & 105.5 & 13888.89 & 3269.44 & 23.54 \\
\hline FWWL-14 & 118 & 161 & 113.5 & 14583.33 & 4713.89 & 32.29 \\
\hline FWWL-15 & 123 & 167 & 128.0 & 14583.33 & 2188.89 & 15.11 \\
\hline FWWL-16 & 125 & 164 & 108.0 & 14027.78 & 3508.33 & 24.99 \\
\hline FWWL-17 & 127 & 163 & 115.5 & 14166.67 & 3536.11 & 24.95 \\
\hline FWWL-18 & 122 & 162 & 104.0 & 13888.89 & 4261.11 & 30.68 \\
\hline $\begin{array}{l}\text { Check-I } \\
\text { (Pirsabak- } \\
\text { 2013) }\end{array}$ & 115 & 152 & 91.0 & 13194.44 & 4683.33 & 36.00 \\
\hline $\begin{array}{l}\text { Check-II } \\
\text { (Pirsabak- } \\
\text { 2005) }\end{array}$ & 117 & 162 & 110.0 & 15972.22 & 4688.89 & 29.39 \\
\hline $\begin{array}{l}\text { Grand } \\
\text { Mean }\end{array}$ & 122 & 161 & 108 & 14361.11 & 3735.35 & 26.25 \\
\hline $\operatorname{LSD}_{(0.05)}$ & 3.62 & 6.83 & 7.59 & $\mathrm{NS}$ & 872.27 & 4.55 \\
\hline
\end{tabular}

Table 4. Genotypic variance (Vg), Error variance (Ve), phenotypic variance (Vp) and Heritability $\left(h^{2}\right)$, genetic advance (GA) and genetic advance $(\%)$ for phenological and yield attributes

\begin{tabular}{|l|l|l|l|l|r|r|}
\hline Traits & $\mathbf{V g}$ & $\mathbf{V e}$ & $\mathbf{V p}$ & $\mathbf{h}^{\mathbf{2}}$ & $\mathbf{G A}$ & $\mathbf{G A}(\boldsymbol{\%})$ \\
\hline Days to heading & 12.73 & 2.99 & 15.72 & 0.81 & 4.49 & 3.69 \\
\hline Days to maturity & 15.22 & 10.64 & 25.86 & 0.59 & 4.19 & 2.61 \\
\hline Plant height & 82.88 & 13.15 & 96.03 & 0.86 & 11.84 & 10.98 \\
\hline Biological yield & 941493.39 & 2667722.55 & 3609215.94 & 0.26 & 693.81 & 4.83 \\
\hline Grain yield & 396083.23 & 173683.19 & 569766.41 & 0.70 & 734.63 & 19.67 \\
\hline Harvest index & 22.39 & 4.73 & 27.12 & 0.83 & 6.02 & 22.93 \\
\hline
\end{tabular}

\section{Days to maturity}

In the current scenario of climatic change wheat improvement programs focuses on development of early maturing cultivars. Wheat scientists are concerned with early maturing wheat cultivars to trim the time 
gap of delay plantation which helps genotypes in diverse ways to survive with several abiotic \& biotic factors. The main advantage of early maturing cultivars is to escape heat and drought stress by finishing their life cycle at earliest. Data revealed highly significant differences $(\mathrm{P} \leq 0.01)$ for maturity among the current wheat lines (Table 2). Similar, significant genotypic differences for physiological maturity were also previously reported by [9]. Maturity in wheat genotypes ranged from 152 to 168 days having average value 162 days. Wheat genotype FWWL-6 was found to be best for taking least days of (152) till maturity (Table 3). Genotypic, phenotypic as well as the error variance were 15.22, 25.86 and 10.64, respectively. Moderate heritability of 0.59 was recorded for maturity. However, the observed genetic advance for days to maturity was low (2.61\%) (Table 4). Our findings are in general agreement with the findings of Abinasa et al. [8] who also reported moderate to low genetic advance for maturity in bread wheat.

\section{Plant height $(\mathbf{c m})$}

Keeping the lodging problem to the farming community plant breeders are more attentive to select plants with moderate to short stature because short plant are more responsive to fertilizers and irrigation and thus are more resistant to lodging. Data revealed highly significant differences $(\mathrm{P} \leq$ 0.01) for plant height among all wheat genotypes (Table 2). Substantial amount of variability in wheat genotypes for many yield traits including plant height were also reported by [13]. Plant height among the genotypes ranging from 87 to $128 \mathrm{~cm}$ having average value $108 \mathrm{~cm}$. wheat genotype FWWL-15 was observed as desirable for as it short stature among the evaluated lines (Table 3) Genotypic, phenotypic as well as error variance 82.88, $96.03 \& 13.15$, respectively. For plant height heritability estimate were high with value of
0.86 and genetic advance was medium $(10.98 \%)$ (Table 4). Our observations are in line with the previously reported finding of $[14,15]$ who observed significant variability and high heritability for plant height in wheat.

\section{Biological yield ( $\left.\mathrm{kg} \mathrm{ha}^{-1}\right)$}

Biological yield is vital factor and scientists emphasized on wheat genotypes with higher biological yield. Among lines, nonsignificant genetic differences $(\mathrm{P} \leq 0.01)$ were observed for biological yield (Table 2). Similar differences among the genotypes for biological yield were also reported by Akçura. M [16]. Among the wheat genotypes the biological yield ranging from 11805.56 to $16666.67 \mathrm{~kg}$ per hectares with average value $14361.11 \mathrm{~kg}$ per hectares. Wheat genotypes FWWL-1 as well as FWWL-12 were attractive for having maximum biological yield as compared to other wheat genotypes evaluated (Table 3). Genotypic, phenotypic as well as error variance were 941493.39, 3609215.94 and 2667722.55, respectively. Low heritability (broad sense) of 0.26 was recorded for biological yield. Genetic advance for biological yield was low (4.83\%) (Table 4$)$. Our results are supported by the findings of Sachan and Singh [17] and Akçura M [16] reported low heritability as well as low genetic advance for yield traits. However, our results are in contrast with the earlier findings of Abinasa et al., [8] whose reported moderate to high heritability for biological yield in evaluating 36 set of spring wheat advanced lines.

\section{Grain yield (kg ha $\left.{ }^{-1}\right)$}

Increase in grain yield is the decisive target of most wheat programs and availability of diversity in breeding material is hence essential for the improvement of grain yield in wheat. Hence, wheat genotypes with more grain yield are very imperative for plant breeders to focus on maximizing wheat production. Highly significant differences $(\mathrm{P}$ 
$\leq 0.01)$ were observed among the wheat lines for grain yield (Table 2). Significant genetic diversity for grain yield among the advanced wheat lines were reported by Afridi et al. [18] and concluded that wheat lines with high grain yield would prove better for improving the head appearances and grain yield. Mean value of grain yield were $3735.35 \mathrm{~kg} \mathrm{ha}$ with range from 1627.78 to $4713.89 \mathrm{~kg} \mathrm{ha}^{-1}$ among the diverse wheat genotype. Wheat genotype FWWL-14 was prominent by shaving higher yield than rest of wheat genotypes (Table 3). Genotypic, phenotypic and error variance were 396083.23, 569766.41 and 173683.19, respectively. Heritability (broad sense) was observed as 0.70 and genetic advance for grain yield was low (19.67\%) for grain yield (Table 4). Our finding are close to Afridi et al. [18] who previously reported moderate to high heritability for grain yield in synthetic wheat.

\section{Harvest index (\%)}

Harvest index is essential parameter \& breeders prefer lines with more harvest index and high yield. Highly significant differences $(\mathrm{P} \leq 0.01)$ among the wheat lines were observed for harvest index (Table 2). Such significant differences for harvest index among the genotypes have also been reported by Akçura M [16] and Abinasa et al. [8]. Among the genotypes harvest index ranging from 11.17 to $36.00 \%$ with average value was $26.25 \%$. Wheat genotype FWWL19 was found to be good genotype with healthier value of harvest index while rests of genotypes were comparatively less value of harvest index (Table 3). Genotypic, phenotypic and error variance were 22.39, 27.12 and 4.73, respectively. Heritability (broad sense) were higher as 0.83 and expected genetic advance for harvest index was high as $22.93 \%$ (Table 4). Sachan \& Singh [17] also observed high magnitude of heritability (0.98) for harvest index in a study on spring wheat.

\section{Conclusion and recommendations}

Information regarding genetic variability and identification of superior germplasm are prerequisites for the success of wheat breeding. Genotypes having required characters are carefully chosen from variable wheat populations. Among winter wheat significant differences were indicating adequate variation existing to do efficient selection. Among the tested lines FWWL-6 and FWWL-14 were earlier in heading, short stature and produced maximum grain yield and could be efficiently used in wheat breeding to make new cultivars with high yield

\section{Authors' contributions}

Conceived and designed the experiments: $\mathrm{M}$ Ishaq, Performed the experiments: G Ahmad \& K Afridi, Analyzed the data: S Ullah, HU Rahman \& A Saleem, Contributed reagents/ materials/ analysis tools: TU Khan, MA Qureshi \& IA Shah, Wrote the paper: M Ali, M Ishaq \& M Saeed.

\section{Acknowledgements}

The authors are thankful to International Center for Agriculture Research in Dry Areas (ICARDA) and CIMMYT Mexico for provision of germplasm and financial support through Wheat Productivity Enhancement Program (WPEP).

\section{References}

1. Minfal (2012-13). Federal Bureau of Statistics, Statistics division, Islamabad, Government of Pakistan.

2. Brant V, Neckář K, Pivec J, Duchoslav M, Holec J, Fuksa $\mathrm{P}$ \& Venclová V (2009). Competition of some summer catch crops and volunteer cereals in the areas with limited precipitation. Plant Soil and Environment 55: 17-24.

3. Singh TP \& Singh KB (1973). Association of grain yield and its components in segregating populations of green gram. Indian J of Genet 33: 112117. 
4. Gashaw AH \& Mohammed H (2007). Selection criterion for improved grain yields in Ethiopian durum wheat genotypes. Afri Crop Sci J 15(1): 25 31.

5. Sabu KK, Abdullah MZ, Lim LS \& Wickneswari R (2009). Analysis of heritability and genetic variability of agronomically important traits in Oryza sativa x Oryza rufipogon crosses. Agron Res $J$ 7(1): 97-102.

6. Borlaug NE \& Dowswell CR (1997). The acid lands: One of agriculture's last frontiers. In: Plant-Soil Interactions at Low pH, Moniz, A.C. (eds). Braz Soil Sci Soci pp. 5-15

7. Allard RW (1960). Principles of plant breeding. John Wiley and Sons, New York.

8. Abinasa M, Ayana A \& Bultosa G (2011). Genetic variability, heritability and trait associations in durum wheat (Triticum turgidum L. var. durum) genotypes. Afri J Agric Res 6(17): 39723979.

9. Tesfaye $\mathrm{T}$, Genet $\mathrm{T} \&$ Desalegn $\mathrm{T}$ (2014). Genetic variability, heritability and genetic diversity of bread wheat (Triticum aestivum L.) genotype in western Amhara region, Ethiopia Wudpecker J Agric Res 3(1): 026 - 034.

10. Tazeen M, Nadia K \& Farzana NN (2009). Heritability, phenotypic correlation and path coefficient studies for some agronomic characters in synthetic elite lines of wheat. J Food Agr Environ 7(3\&4): 278-282.

11. Chandrababu RJ \& Sharma RK (1999). Heritability estimates in almond [Prunus dulcis (Miller) D.A. Webb]. Sci Hortic 79: 237-243.

12. Gupta SK \& Verma SR (2001). Variability, heritability and genetic advance under normal and rainfed conditions in durum wheat (Triticum durum Desf.). Indian J Agric Res 122125.

13. Ali Y, Atta BM, akhter J, Monneveux P \& Lateef Z (2008). Genetic variability, association and diversity studies in wheat (Triticum aestivum L.) Germplasm. Pak J Bot 40(5): 20872097.

14. Korkut K, Baser I \& Bilgin O (2001). Genotypic and phenotypic variability, heritability and phenotypic correlation for yield and yield components in bread wheat varieties. Acta-Ag Ronomica, 43: 237-242.

15. Sharma AK \& Garg DK (2002). Genetic variability in wheat (Triticum aestivum L.) crosses under different normal and saline environments. Annals Agric Res 23(3): 497-499.

16. Akçura M (2009). Genetic variability and interrelationship among grain yield and some quality traits in Turkish winter durum wheat landraces. Turk J Agric For 33: 547-556.

17. Sachan MS \& Singh SP (2003). Genetics of yield and its components in durum wheat. J Interacademicia 7(2): 140-143.

18. Afridi K, Ahmad G, Ishaq M, Khalil IA, Shah IA, Saeed M \& Ahamd N (2014). Genetic potential and variability for morpho-yield traits in duram wheat (Triticum turgidum 1. Var. Durum). Intl J Farm \& Alli Sci 3 (12): 1206-1212. 